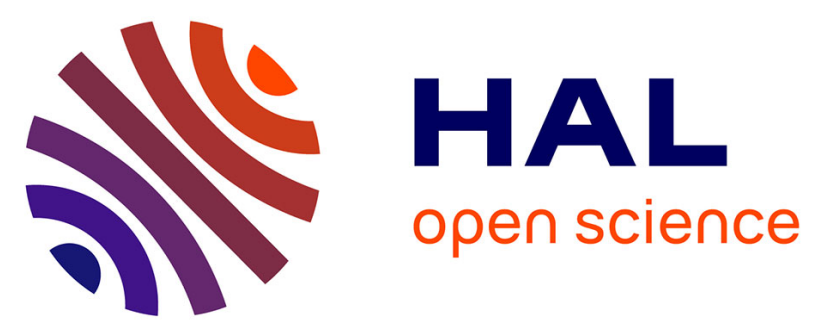

\title{
Analysis of a new analytical law of Heat Release Rate (HRR) for Homogeneous Charge Compression Ignition (HCCI) combustion mode versus analytical parameters
}

Miguel Torres Garcia, Francisco J. Jiménez-Espadafor Aguilar, José A. Becerra Villanueva, Elisa Carvajal Trujillo

\section{To cite this version:}

Miguel Torres Garcia, Francisco J. Jiménez-Espadafor Aguilar, José A. Becerra Villanueva, Elisa Carvajal Trujillo. Analysis of a new analytical law of Heat Release Rate (HRR) for Homogeneous Charge Compression Ignition (HCCI) combustion mode versus analytical parameters. Applied Thermal Engineering, 2010, 31 (4), pp.458. 10.1016/j.applthermaleng.2010.09.025 . hal-00699056

\section{HAL Id: hal-00699056 https://hal.science/hal-00699056}

Submitted on 19 May 2012

HAL is a multi-disciplinary open access archive for the deposit and dissemination of scientific research documents, whether they are published or not. The documents may come from teaching and research institutions in France or abroad, or from public or private research centers.
L'archive ouverte pluridisciplinaire HAL, est destinée au dépôt et à la diffusion de documents scientifiques de niveau recherche, publiés ou non, émanant des établissements d'enseignement et de recherche français ou étrangers, des laboratoires publics ou privés. 


\section{Accepted Manuscript}

Title: Analysis of a new analytical law of Heat Release Rate (HRR) for Homogeneous Charge Compression Ignition $(\mathrm{HCCl})$ combustion mode versus analytical parameters

Authors: Miguel Torres Garcia, Francisco J. Jiménez-Espadafor Aguilar, José A. Becerra Villanueva, Elisa Carvajal Trujillo

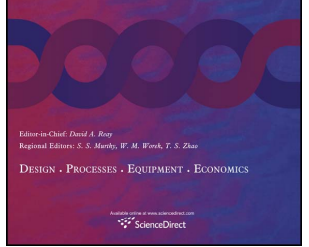

PII:

$$
\text { S1359-4311(10)00421-7 }
$$

DOI: 10.1016/j.applthermaleng.2010.09.025

Reference: $\quad$ ATE 3252

To appear in: Applied Thermal Engineering

Received Date: 14 June 2010

Revised Date: 27 September 2010

Accepted Date: 28 September 2010

Please cite this article as: M.T. Garcia, F.J. Jiménez-Espadafor Aguilar, JA. Becerra Villanueva, E.C. Trujillo. Analysis of a new analytical law of Heat Release Rate (HRR) for Homogeneous Charge Compression Ignition $(\mathrm{HCCl})$ combustion mode versus analytical parameters, Applied Thermal Engineering (2010), doi: 10.1016/j.applthermaleng.2010.09.025

This is a PDF file of an unedited manuscript that has been accepted for publication. As a service to our customers we are providing this early version of the manuscript. The manuscript will undergo copyediting, typesetting, and review of the resulting proof before it is published in its final form. Please note that during the production process errors may be discovered which could affect the content, and all legal disclaimers that apply to the journal pertain. 


\title{
Analysis of a new analytical law of Heat Release Rate (HRR) for Homogeneous Charge Compression Ignition (HCCI) combustion mode versus analytical parameters
}

Miguel Torres Garcia ${ }^{*}$, Francisco J. Jiménez-Espadafor Aguilar, José A. Becerra Villanueva, Elisa Carvajal Trujillo

Thermal Power Group, Department of Energy Engineering, University of Seville

Escuela Técnica Superior de Ingenieros de Sevilla, Camino de los Descubrimientos, s/n. 41092 Sevilla, España

*Corresponding author. Tel.:+34954486111; fax: +34954487243. E-mail: miguel_torres@esi.us.es (Miguel Torres García)

\begin{abstract}
Homogeneous charge compression ignition (HCCI) engines produce very low $\mathrm{NO}_{\mathrm{x}}$ and soot emissions and also improve engine efficiency when compare to conventional spark ignition engines. The combustion process bases on the self-ignition of a homogenous air-fuel mixture without an external ignition source. The gas temperature is very important to initiate the combustion and to promote the appropriate chemical kinetics. As a result, the heat release rate and heat transfer inside the combustion chamber play a significant role in the HCCI combustion mode. The high relevance of gas temperature on this combustion mode means that heat transfer is considered through a dedicated heat transfer model. In this system the forced convection from hot gases to the combustion chamber walls is the dominant heat transfer mechanism. This paper focuses
\end{abstract}


on the relationship between HRR in HCCI combustion mode and the four parameters that are required for an analytical function to model this heat release rate. More specifically, the influences of the fuel-air equivalence ratio, engine speed and EGR on the four parameters that control HRR are examined. The analytical HRR law is validated over a wide range of operating conditions in HCCI combustion mode and shows that these four parameters are directly related to any load condition, including engine speed, fuel rate and EGR. These parameters can therefore be used to characterize this combustion mode.

Keywords: HRR (heat release rate); EGR (exhaust gas recirculation); HCCI (homogeneous charge compression ignition).

\section{Nomenclature}

$\bar{S}_{p}$

$A_{c}$

$a_{1,} a_{2}$

ATDC

BDC

BTDC

$\mathrm{C}_{1}, \mathrm{C}_{2}$

CFD

$\mathrm{CO}_{2}$

DI

EGR
Mean piston speed (m/s)

Common area of heat transfer

Shape factors for HRR

After top dead center

Bottom dead center

Before top dead center

Constants

Computational Fluid Dynamics

Carbon dioxide

Direct injection

Exhaust Gas Recirculation 


\begin{tabular}{|c|c|}
\hline $\mathrm{H}_{2} \mathrm{O}$ & Water \\
\hline$h_{c}$ & Heat transfer coefficient \\
\hline HCCI & Homogeneous Charge Compression Ignition \\
\hline HRR & Heat Release Rate \\
\hline$K_{1}, K_{2}$ & Terms of HRR law \\
\hline LHV & Lower Heat Value \\
\hline$\dot{m}$ & Mass flow (kg/s) \\
\hline$M_{p}, M_{p p}$ & Shape factors \\
\hline$P, p$ & Pressure (bar) \\
\hline$Q$ & Heat $(J)$ \\
\hline$Q_{p}$ & Heat release in HCCI combustion mode $(\mathrm{J})$ \\
\hline$Q_{W}$ & Wall heat loss $(\mathrm{J})$ \\
\hline RPM & Revolutions per minute \\
\hline SI & Spark ignition \\
\hline$T$ & Temperature $(\mathrm{K})$ \\
\hline TDC & Top dead center \\
\hline$T_{g}$ & Gas temperature $(\mathrm{K})$ \\
\hline$T_{W}$ & Cylinder wall temperature $(\mathrm{K})$ \\
\hline$V$ & Volume $\left(\mathrm{m}^{3}\right)$ \\
\hline$V_{d}$ & Displacement \\
\hline$W$ & Power (W) \\
\hline
\end{tabular}

Greek letter 


$\begin{array}{ll}\theta & \text { Crankshaft angle (radians) } \\ \theta_{p} & \text { Duration of the energy release (radians) } \\ \Phi & \text { fuel/air equivalence ratio } \\ \omega & \text { Angular speed ( } \mathrm{rad} / \mathrm{s}) \\ \alpha_{\text {scaling }} & \text { Scaling factor }\end{array}$

\section{$\underline{\text { 1. INTRODUCTION }}$}

Homogeneous charge compression ignition (HCCI) engines are attracting a great deal of attention as the next generation of internal combustion engine, mainly because of their very low $\mathrm{NO}_{\mathrm{x}}$ and soot emissions but also due to the improved engine efficiency when compared to conventional spark ignition engines [1-3]. HCCI combustion integrates features of both spark ignition (SI) and compression ignition (CI) engines to give promisingly the high efficiency of a diesel engine with virtually zero $\mathrm{NO}_{\mathrm{x}}$ and soot emissions[4,5,6 The combustion process is based on the self-ignition of a homogenous air-fuel mixture without an external ignition source. The gas temperature is very important to initiate the combustion and to promote the appropriate the chemical kinetics. For this reason, the heat release rate and heat transfer inside the combustion chamber play a significant role in the HCCI combustion mode.

The rate of heat release in HCCI combustion mode is not controlled by the rate of fuel injection (as it is in DI engines) nor by finite turbulent flame propagation (as in SI engines). The absence of an ignition control mechanism has led researchers to explore a range of control strategies. However, performing these explorations solely in the laboratory would be inefficient, expensive and impractical since there are numerous 
variables that are involved in complex interactions. A great deal of research activity has been carried out on global heat transfer models, e.g. by Annand [7], Woschni [8] and Hohenberg [9], and these have concerned engine conditions that vary significantly from those in HCCI combustion. The dominant heat transfer mechanism in HCCI combustion mode is forced convection from hot gases to the combustion chamber walls. The very low level of soot formation and relatively low bulk gas temperature mean that the radiation effect in this system is very small; a situation in contrast to the case of the conventional diesel combustion mode. For this reason, any HRR analysis for the HCCI combustion mode should be developed through a dedicated heat transfer model. In this paper, the model described by Junseok Chang was considered [10].

A significant amount of research is focused on obtaining an analytical function to model the heat release rate in HCCI combustion mode as this would facilitate combustion analysis and avoid the development of intensive tests and CFD calculus [11, 12].

The HRR for the HCCI process presents a premixed combustion shape while that of the diesel combustion mode includes premixed and diffusive contributions [13, 14]. The work described here involved the analysis of an HRR model developed for the HCCI combustion mode [15]. The influences of the fuel-air equivalence ratio and EGR on the four parameters that control HRR were examined.

The development of an analytical HRR law validated over a wide range of operating conditions in HCCI combustion mode represents a significant advance in our understanding of HCCI combustion and also allowed the development of a predictive [15] computational model for this combustion process.

\section{ENGINE AND EXPERIMENTAL SETUP}


The experimental part of this work was based on tests carried out on the DEUTZ FL1 906 engine [16-17]. The original diesel engine was modified to adapt it to HCCI combustion, the injection point was fixed and different operating conditions (e.g., engine speed, air/fuel ratio and intake temperature) were tested. The specifications of the original diesel engine were as follows: cylinder bore $95 \mathrm{~mm}$, stroke $100 \mathrm{~mm}$, displacement $708 \mathrm{~cm}^{3}$, nominal compression ratio $19: 1$ and rated power of $13 \mathrm{~kW}$ at 3000 RPM. Commercial diesel fuel compatible with European Standard EN590 was used in all tests and the fuel properties are shown in Table 1. Systematic tests were carried out with the angle of injection fixed at $45^{\circ}$ BTDC. The load was changed from a low load up to the maximum attainable load for the engine in HCCI combustion mode. An increase in the engine load, without EGR, leads to an advance in the start of combustion, an increase in the maximum pressure and also an advance in the crankshaft angle at which maximum pressure is reached. The maximum attainable load was established in order to ensure the mechanical integrity of the engine. The maximum pressure was limited at top dead center to 110 bar, which corresponds roughly to $20 \mathrm{Nm}$ with the engine running without EGR at 1200 RPM, a compression ratio of 19:1 and a charge temperature of $18^{\circ} \mathrm{C}$.

The range of engine speeds studied was from 1200 RPM to 2400 RPM in intervals of 300 RPM.

TABLE 1

The recirculated gases (EGR) were cooled in order to control the intake temperature and ensure that this never surpassed the ambient temperature; the effect of inlet temperature on HCCI is well known. The external EGR rate was evaluated by measuring the EGR mass recirculated and the total mass inlet. The formula is as follows: 
$E G R(\%$ mass $)=\frac{\dot{m}_{E G R}}{\dot{m}_{E G R}+\dot{m}_{\text {Air }}} \cdot 100$

where $\dot{m}_{E G R}$ and $\dot{m}_{A i r}$ were measured with a hot wire flow meter.

\section{MODEL FOR THE EVALUATION OF THE HRR}

In this work a thermodynamic zero-dimensional model was used to analyze and evaluate the parameters of an analytical law for HRR by following an iterative optimization process. Equations and simplifications that govern the mathematical model are needed due to the complex interactions between physical and chemical phenomena during combustion and these are described in the following equations [18], where blow by was not considered:

- Thermal state equation

- Combustion chamber volume

- First Principle of Thermodynamics [16]

- Heat losses

The heat loss model is written as follows:

$$
\frac{d Q_{W}}{d \theta}=A_{c} h_{c}\left(T_{g}-T_{W}\right) \frac{1}{\omega}
$$

A lot of research can be found about heat transfer in internal combustion engines, but almost all of the models have been developed for spark and compression ignition engines. HCCI combustion process is quite different from that of spark or compression ignition engines. In this way the research of Junseok Chang [10] is devoted only to this type of combustion and it has been thoroughly validated in its paper and for these reasons only has been considered this heat losses model. 
The heat transfer coefficient $h_{c}\left(\mathrm{~W} / \mathrm{m}^{2} \mathrm{~K}\right)$ is based on the correlation formula given by Junseok Chang [10]. $Q_{W}$ is the wall heat loss, $A_{c}$ is the area in contact with the gases, $T_{g}(\mathrm{~K})$ is the gas temperature, $T_{w}(\mathrm{~K})$ is the cylinder wall temperature and $\omega(\mathrm{rad} / \mathrm{s})$ is the average angular speed. The global heat transfer coefficient can be written as:

$h_{c}(t)=\alpha_{\text {scaling }} L(t)^{-0.2} p(t)^{0.8} T(t)^{-0.73} v(t)^{0.8}$

A scaling factor $\alpha_{\text {scaling }}$ is used to tune the coefficient to match a specific engine geometry. Combustion-induced gas velocity is a function of the difference between motoring and firing pressure.

$$
v(t)=C_{1} \bar{S}_{p}+\frac{C_{2}}{6} \frac{V_{d} T_{r}}{p_{r} V_{r}}\left(p-p_{\text {motoring }}\right)
$$

The main reason for using this equation is to keep the velocity constant during the nonfiring period of the cycle and to then impose a steep velocity rise once the combustion pressure departs from motoring pressure. The subscript $r$ denotes a reference crank angle, such as the intake valve closing.

\section{ANALYTICAL LAW FOR HRR IN HCCI COMBUSTION MODE}

In this work a newly developed model for HRR has been analyzed. The HRR curves for a constant angular speed of $1200 \mathrm{RPM}$, inlet temperature of $18^{\circ} \mathrm{C}$, compression ratio of 19:1 and different injected fuel levels are shown in Figure 1. These curves reveal the very high heat release rate that causes a rapid increase in combustion pressure. As a consequence, combustion is characterized by the sudden steep pressure rise on the cylinder pressure curve and by the peak in the HRR. Once the previously formed flammable mixture has been completely burnt, the HRR decreases until the end of 
combustion. The HRR showed the same trend for all fuel consumption rates, engine speeds and EGR rates tested in HCCI mode.

\section{FIGURE 1}

Therefore, combustion is completely controlled by chemical kinetics. The gas cylinder temperature is not sufficiently high and therefore the fuel does not reach pyrolysis conditions, thus almost completely avoiding soot formation and diminishing $\mathrm{NO}_{\mathrm{x}}$ formation markedly $[19,20]$.

A model for the HRR that can be adapted efficiently to a combustion process controlled only by chemical kinetics was developed by Wiebe. In this work, this scenario has been analyzed using a modified Wiebe function that allowed the formulation of a new HRR law that fits quite well to the HCCI combustion process [21,22].

$$
\frac{d Q}{d \theta}=a_{1} \frac{Q_{p}}{\theta_{p}}\left(M_{p}+1\right)\left(\frac{\theta}{\theta_{p}}\right)^{M_{p}} \exp \left[-a_{2}\left(\frac{\theta}{\theta_{p}}\right)^{M_{p p}+1}\right]
$$

Where $a_{1}, a_{2}, M_{p}, M_{p p}$ are shape factors. In order to reproduce the HRR it was necessary to consider the parameter $M_{p}$ to be different from the parameter $M_{p p}$ (the opposite of the original Wiebe function), see equation (5). $\theta_{p}$ is the duration of the energy release and $Q_{p}$ characterizes the heat release in HCCI combustion mode.

Defining the terms:

$$
K_{1}=a_{1} \frac{Q_{p}}{\theta_{p}^{M_{p}+1}}\left(M_{p}+1\right) \quad K_{2}=a_{2} \frac{1}{\theta_{p}^{M_{p p}+1}}
$$

It follows that the HRR is:

$$
\frac{d Q}{d \theta}=K_{1} \theta^{M_{p}} \exp \left[-K_{2} \theta^{M_{p p}+1}\right]
$$

\section{INFLUENCE OF ANALYTICAL LAW PARAMETERS ON THE SHAPE OF HRR}


An engine in HCCI combustion mode operates under variable conditions. The fuel/air equivalence ratio, engine speed and EGR range are the three main operating factors that affect HCCI engine performance and therefore the HRR associated with each set of operating conditions. In this section the cause-effect relationship between the four parameters of the HRR analytical law (defined in section 4) and HRR shape and magnitude are discussed in terms of actual test results. The analysis was initiated with an experimental test based on the following conditions: engine speed 1800 RPM, EGR rate $5 \%$ in mass and injected fuel of $9 \mathrm{e}^{-6} \mathrm{~kg} /$ cycle, which corresponds to values of 0.5 , 50, 3.75 and 0.73 for $\mathrm{K} 1, \mathrm{~K} 2, \mathrm{Mp}$ and Mpp, respectively.

The analysis was performed by changing one parameter and maintaining the rest constant. The range adopted for $\mathrm{K} 1, \mathrm{~K} 2, \mathrm{Mp}$ and Mpp is given in Table 2 along with the main results of the HRR analytical law. This range was designed so that, for each parameter, the maximum range increment divided by the mean range value is constant for the four parameters and is equal to 0.4. This normalization allows the influence of each parameter on HRR to be studied while avoiding distortion of the results due to numerical effects.

The five HRR laws for each of the analyzed parameters in Table 2 are represented in Figure 2. It can be observed in Figure 2a that the maximum value of HRR increases with $\mathrm{K} 1$ while the combustion duration and angular position of the HRR maximum are constant. Therefore this parameter evolves as a gain control of HRR, with a linear relationship between $\mathrm{K} 1$ and the maximum of HRR. The effect of $\mathrm{K} 2$ on HRR is represented in Figure $2 \mathrm{~b}$; it can be seen that both combustion duration and the HRR maximum increase as $\mathrm{K} 2$ diminishes. In this case the relationship between $\mathrm{K} 2$ and the 
maximum of HRR is almost quadratic. The effect of Mp growth on HRR is shown in Figure 2c. In this case the maximum of HRR is extremely sensitive to changes in Mp when compared with $\mathrm{K} 1$ and $\mathrm{K} 2$. Furthermore, as $\mathrm{K} 2$ increases the start of the combustion process advances. Finally, the changes in HRR as Mpp is modified are shown in Figure $2 \mathrm{~d}$. The behavior observed is very similar to that for K2.

FIGURE 2

The analysis is summarized in the following table:

TABLE 2

6. INFLUENCE OF FUEL/AIR EQUIVALENCE RATIO AND EGR RATE ON

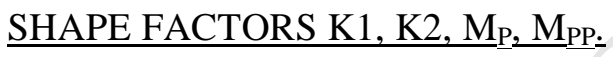

\section{$\underline{6.1 \text { FUEL/AIR EQUIVALENCE RATIO EFFECT }}$}

A study of the influence of the air equivalence ratio on HRR and emissions from experimental results is discussed in this section. Results for the engine performance in HCCI combustion mode from experimental data for four fuel/air equivalence ratios at 1200 RPM are given in Table 3 and the combustion pressure chamber and HRR for these test conditions are shown in Figure 1. The dashed line corresponds to experimental tests, where HRR was obtained from a zero-dimensional model fed from the combustion chamber pressure and all the test data [16]. The solid lines correspond to results modeled using the approach developed in section 3; it can be observed that the 
new HRR law fits every fuel/air ratio tested. From the minimum value, each increment in the fuel/air equivalence ratio has the following effects on the combustion process:

- An advance in the start of combustion

- An increase in the maximum heat release rate and maximum combustion chamber pressure

- A reduction in combustion duration

- An increase in exhaust temperature

- An increase in $\mathrm{NO}_{\mathrm{x}}, \mathrm{CO}, \mathrm{HC}$ and soot emissions

- An increase in specific fuel consumption

\section{TABLE 3}

An increase in the fuel/air equivalence ratio delivers more energy into the combustion chamber and this in turn heats the piston, cylinder and inlet collector, thus increasing the temperature of these components. The air and fuel are heated and chemical kinetics, which are controlled mainly by gas temperature, are favored - a situation that advances the start of combustion, reduces the combustion duration and delivers more energy before top dead center as more fuel is burnt. As a result, the maximum pressure also increases from 81 to 93 bar. The observed increase in $\mathrm{NO}_{\mathrm{x}}$ can also be explained by the increase in temperature, with the Zeldovich mechanism considered the most important for the promotion of this emission $[23,24]$. However, the increase in soot emissions can be ascribed to both a reduction in the available oxygen as the fuel/air ratio increases and to the loss of gas homogeneity. It must be noted, however, that the combustion process should be considered as homogenous, mainly because of the very low $\mathrm{NO}_{\mathrm{x}}$ level and the 
evolution of the HRR (see Figure 1), where there is no evidence of diffusive combustion. An increase in the exhaust gas temperature is also a consequence of the increased fuel mass injected, even though all the fuel is burnt faster and in advance when compared to the lower fuel/air equivalence ratios.

The moderate increase in specific fuel consumption must be analyzed together with the evolution of combustion pressure and $\mathrm{CO}$ and $\mathrm{HC}$ emissions, because all of these factors increase with fuel flow. The advance in the start of combustion increases the maximum pressure after top dead center and therefore increases imep. However, combustion pressure also increases before top dead center and this is negative work that has to be given by the piston to the gases, a situation that partially counter balances positive work. At the end of the cycle the engine torque increase is less than proportional with the fuel flow. The growth in $\mathrm{CO}$ and $\mathrm{HC}$, mainly due to low temperature combustion and the reduction in available oxygen, reveals a reduction in combustion efficiency, which in turn increases the specific fuel consumption.

The values of the four parameters of the HRR analytical law applied to the cases shown in Figure 1 are presented in Table 4. These parameters for all cases studied at different engine speeds and two EGR rates are plotted against injected fuel flow in Figure 3. At an EGR of the zero parameter K1 [see Figure 3 (a1)] increases with injected mass flow for all engine speeds except for the highest (i.e. 2100 RPM). This reveals that the HRR maximum increases in this case with fuel flow, but at higher engine speeds the start of the combustion angle is delayed too much and the combustion duration in crankshaft angle is also increased, thus making the maximum HRR almost constant. This behavior is more marked for $23 \%$ EGR [Figure 3 (b1)] and, as a result, at the maximum engine speed $\mathrm{K} 1$ diminishes with injected fuel, giving rise to a reduction in combustion intensity. At zero EGR the parameter K2 is almost independent of fuel consumption at 
2100 RPM [see Figure 3 (a2)] but K2 decreases as engine speed decreases, which shows an increase in combustion intensity and combustion duration. For 23\% EGR [see Figure 3 (b2)] it seems that $\mathrm{K} 2$ - injected fuel curves pivot increasing K2 for the same injected fuel, this is, there is an increase of combustion duration and of the maximum of HRR. The parameter Mp is very sensitive to engine speed for low levels of injected fuel, showing in this case that the lower the engine speed the higher the combustion duration and the higher the maximum of HRR, see Figure 3 (a3). This dependence on the engine speed diminishes markedly at high fuel flow and is almost constant near the maximum at $0.03 \mathrm{~g} /$ cycle. At this point there is compensation through an advance in the start of combustion, an increase in combustion duration and the reduction of available time for combustion for the same crankshaft angle. This trend changes with $23 \%$ EGR [see Figure 3 (b3)], for which the compensation point has moved to lower fuel flow near to $0.02 \mathrm{~g} /$ cycle. From this point $\mathrm{K} 2$ increases with engine speed and reaches a maximum at $0.03 \mathrm{~g} /$ cycle, which could be related to the promotion of fuel homogeneity due to an increase in turbulence intensity with engine speed. For zero EGR, see Figure 3 (a4), the parameter Mpp is quasi-linear with injected fuel flow for all engine speeds. The slope of the line reduces with engine speed and becomes negative at 1200 RPM. For 23\% EGR, see Figure 3 (b4), Mpp has a more uniform behavior for all engine speeds and always has a positive slope, with the highest values observed at $2100 \mathrm{RPM}$ and the lowest at 1200 RPM.

\section{TABLE 4}

FIGURE 3

\section{$\underline{\text { 6.2 EGR RATE EFFECT }}$}


EGR is a very well known method for $\mathrm{NO}_{\mathrm{x}}$ reduction in diesel engines and is also a method in HCCI combustion mode, when fuelled with commercial fuel, to improve engine power - mainly because of the increase in the ignition delay $[25,26]$. The experimental tests with EGR were carried out from an initial load condition without EGR (i.e. with fuel consumption, engine speed, injection fuel angle and compression ratio constant) and the percentage of EGR was then progressively increased. This gradual increase in EGR had a direct influence on the charge intake temperature at intake valve closing (IVC).

The percentage of EGR produces a delay on the ignition, which depends on fuel consumption and engine speed. At constant RPM, it was observed that for low loads the maximum percentage of EGR is greater than at high loads. Furthermore, the effect of EGR is similar to that produced by an increase in the engine speed: both factors combine to increase the ignition delay. The percentage of EGR depends on the thermal capacity of the composition of the exhaust gases (quantity of $\mathrm{CO}_{2}, \mathrm{H}_{2} \mathrm{O}$ and $\mathrm{O}_{2}$ ); at low loads the exhaust gases have a minimal proportion of $\mathrm{CO}_{2}$ and $\mathrm{H}_{2} \mathrm{O}$ and, therefore, a lower thermal capacity.

The EGR rate was characterized by $\mathrm{m} \cdot \overline{C_{p}}(\mathrm{~J} / \mathrm{K})$, which is the product of the intake mass and the mean specific heat of the gas mixture, evaluated at the temperature at which combustion starts (as provided by the combustion model).

An example of engine performance and combustion comparison at 2100 RPM and $0.027 \mathrm{~g} /$ cycle injected fuel is shown below.

\section{TABLE 5}

It can be seen from the results in Table 5 that when the EGR rate rises from 5\% to $28 \%$ by mass, the engine SFC increases by about $26 \%$ (from 0.261 to $0.380 \mathrm{~kg} / \mathrm{kWh}$ ). The peak cylinder-firing pressure decreased (from 72 to 96 bar), indicating a lower 
combustion rate. The smoke (0.3 vs. 0.7 Bosch number) and exhaust temperature $\left(423^{\circ} \mathrm{C}\right.$ vs. $\left.562^{\circ} \mathrm{C}\right)$ increased as a result of late burning.

It can be observed that when the EGR is $20 \%$ by mass, $\mathrm{NO}_{\mathrm{x}}$ emissions remain constant with fuel consumption; without $\mathrm{EGR}$ the $\mathrm{NO}_{\mathrm{x}}$ emissions increase with fuel consumption. Combustion pressure and HRR corresponding to the results in Table 5 are shown in Figure 4, where simulated cylinder pressures are compared with measured ones derived from the experimental study. Quite good agreement between experimental and modeled results can be observed. The modeled cylinder pressures were obtained from the new HRR law for different mass flows and EGR levels. In terms of the area under the pressure curve between IVC and EVO, the maximum error is about 1\%. An interesting aspect to highlight is the good reproduction of pressure during the combustion process when an abrupt increase in pressure occurs.

FIGURE 4

As can be observed, the new HRR law adapts perfectly to any EGR rate. From the minimum EGR rate $(5 \%)$, each increment in this parameter has three effects on the HRR:
a) A delay in the start of combustion.
b) A diminution of the maximum heat release rate.
c) An increase in the combustion duration.

The increase in torque is due to the diminution of combustion pressure along the compression stroke, which in turn is due to the delay in the start of combustion (effect a). As a result, power increases at the same engine speed and fuel consumption and there is also an improvement in the engine's specific fuel consumption to weight of effect c, which reduces thermodynamic efficiency [27]. Effect b produces a diminution in the combustion chamber temperature and this will result in a diminution of $\mathrm{NO}_{\mathrm{x}}$ 
emissions and exhaust temperature [28]. The parameters for the simulated HRR are shown in Table 6.

\section{TABLE 6}

The values of the four parameters of the HRR analytical law applied to the cases shown in Figure 4 are presented in Table 6. These parameters for all cases studied at engine speeds of 1200 and 1800 RPM at three fuel rates are presented versus thermal capacity in Figure 5. Parameter K1 shows the same tendency at 1200 and 1800 RPM for all fuel rates and the relationship with thermal capacity is almost linear, see Figures 5 (a1) and 5(b1). At 1200 RPM parameter K1 is always higher for the maximum fuel rate regardless of the $\mathrm{m} \cdot \mathrm{Cp}$ value. However, at $1800 \mathrm{RPM}$ this behavior changes and for the higher thermal capacity the minimum fuel rate presents the maximum $\mathrm{K} 1$. It is also worth noting that the $\mathrm{K} 1$ slope changes from positive $\left(1.5 \mathrm{e}^{-5} \mathrm{~kg} / \mathrm{cycle}\right.$, minimum fuel rate) to negative (2.2 $\mathrm{e}^{-5}$ and $\left.1.5 \mathrm{e}^{-5} \mathrm{~kg} / \mathrm{cycle}\right)$, with the slope becoming more negative as the fuel rate increases. Plots of K2 versus thermal capacity are shown in Figures 5 (a2) and 5 (b2), with the relationship increasing for all engine speeds and fuel rates in the low thermal capacity range. This reveals that combustion intensity increases as the thermal capacity decreases. However, at 1800 RPM all of the curves present a maximum, which reveals an increase in combustion intensity and combustion duration from this thermal capacity value. This behavior can be explained in terms of the expected increase in charge homogeneity with EGR rate and engine speed. The parameter Mp shows a linear relationship with thermal capacity and this is almost identical at 1200 and 1800 RPM, see Figures 5 (a3) and 5 (b3). However, there is a marked slope change between the different fuel rates and this change from a positive slope at $1.5 \mathrm{e}^{-5} \mathrm{~kg} / \mathrm{cycle}$ to a negative slope for higher fuel rates. Furthermore, the slope 
becomes more negative as the fuel rate increases. Close to a thermal capacity of $0.5 \mathrm{~J} / \mathrm{K}$, Mp is almost constant with respect to $\mathrm{m} \cdot \mathrm{Cp}$.

The parameter Mpp also shows a linear relationship with thermal capacity and this is again almost the same at 1200 and 1800 RPM, see Figures 5 (a4) and 5 (b4). The slope of the line decreases with injected fuel and is negative for the $2.8 \mathrm{e}^{-5} \mathrm{~kg} / \mathrm{cycle}$. At 1800 RPM, see Figure 5 (b4), Mpp shows the same behavior for all engine speeds, i.e., with a positive and negative slope, respectively, with the highest value at $1.5 \mathrm{e}^{-5} \mathrm{~kg} / \mathrm{cycle}$ injected fuel and the lowest at $2.8 \mathrm{e}^{-5} \mathrm{~kg} /$ cycle.

\section{FIGURE 5}

\section{CONCLUSIONS}

An experimental and simulation study has been carried out that provides a detailed understanding of the HCCI combustion mode through the analysis of HRR.

The new HRR law was implemented in an engine model to evaluate performance in comparison to the experimental data obtained in the laboratory. The new HRR law allows the cylinder pressure curve to be predicted with minimum error and shows a very good match to the experimental data.

The developed HRR law has shown that four suitable parameters (K1, K2, Mp and Mpp) are sufficient to model the heat release rate. These parameters control the main characteristics of HRR and these are shape, maximum value, maximum angle position and combustion duration.

The experimental analysis performed showed that these four parameters are directly related to any load condition, including engine speed, fuel rate and EGR. Research is in progress to develop a sensitive analysis of these parameters on HRR. 


\section{ACKNOWLEDGMENTS}

The work described in this paper is a part of the project CTQ2007-68026-CO2-02/PPQ within the I+D+i national plan in the period 2007-2009 and was supported by the Spanish Government (Ministry of Science and Education). The authors are grateful to the Ministry of Science and Education of Spain for their financial support.

1. Thring. R.H. "Homogeneous Charge Compression Ignition (HCCI) Engines." SAE Paper No.892068.

2. Aceves, S.M., Flowers, D.L., Westbrook, C.K., Smith, J.R., Pitz, W.J., Dibble, R., HCCI combustion and emissions, Paper No 2000-01-0327.

3. Christensen, M., Johanson, B., Ammeus, P., Mauss, F., (1998) Supercharged Homogeneous Charge Compression Ignition, SAE Paper No 980787.

4. Kimura, S. Aoki, O. Ogawa, H. Muranaka, S. Enomoto, Y. New combustion concept for ultra-clean and high-efficiency small DI diesel engines, SAE Paper 1999-01-3681, 1999.

5. Mainboom Alain Tauzia Xabier, Hétet Jean-Francois, Influence of EGR unequal from cylinder on NOx-PM trade-off a HSDI automotive Diesel engine, Applied Thermal Engineering 29(2009) 2043-2050.

6. Sher, I.Levinzon-Sher, D. Sher, E. Minituarization limitations of HCCI internal combustion engines, Applied Thermal Engineering 29(2009) 400-411

7. Annand, W.J.D. (1963). "Heat Transfer in the Cylinders of Reciprocating Engines.” Proc. Inst. Mech. Engrs. Vol. 177. No. 36.

8. Woschni, G. (1967). "Equation for the Instantaneous Heat Transfer Coefficient in the Internal Combustion Engine" SAE Paper 670931. 
9. Hohenberg, G.F. "Advanced Approaches for Heat Transfer Calculations”. SAE Paper 790825.

10. Chang, J.,Orgun, G. Zoran, F. Assanis, D. Kuo, T-W. Najt, P. Rask, R. “New heat Transfer Correlation for an HCCI engine derived from measurements of instantaneous surface heat flux". SAE Paper 2004-01-2996.

11. Kusaka, J. Yamamoto, T. Daisho, Y. Kihara, R. Saito, T and Shinjuku, O. "Predicting Homogeneous Charge Compression Ignition Characteristics of various Hydrocarbons." Proceedings of the $15^{\text {th }}$ Internal Combustion Engine Symposium (International), Seoul, Korea (1999).

12. Kong, S-C., Reitz. R.D. (2000). "Use of Detailed Chemical Kinetics to Study HCCI Engine Combustion with Consideration of Turbulent Mixing Effects.” Paper 2000-ICE-306. Proceedings of ASME-ICE Fall Technical Conference, ICE-Vol.35-1.

13. Shimazaki, N., Akagawa, H., Tsujimura, K., "An experimental study of premixed lean diesel combustion.” SAE Technical Paper, No. 1999-010181(1999).

14. Xingcai, L. Yuchun, H. Libin, J. Linlin, Z and Zhen, H. Heat Release Analysis on Combustion and Parametric Study on Emissions of HCCI Engines Fuelled with 2-Propanol/n-Heptane Blend Fuels, Enegy and Fuels 2006, 20, 1870-1878.

15. Torres Garcia, M.; Jimenez-Espadafor Aguilar, F.; Carvajal Trujillo, E.; Becerra Villanueva, J.A. Predictive modelling of a homogeneous charge compression ignition (HCCI) engine with EGR fuelled with diesel. Energy and Fuels 23(2009).5383-5393.

16. Torres Garcia, M.; Jimenez-Espadafor Aguilar, F.; Sanchez Lencero, T.; Becerra Villanueva, J.A. A new Heat release rate (HRR) law for Homogeneous Charge 
Compression Ignition (HCCI) combustion mode. Applied Thermal Engineering 29(2009). 3654-3662.

17. Torres Garcia, M. Jimenez-Espadafor Aguilar, F. Chacartegui Ramirez, R.

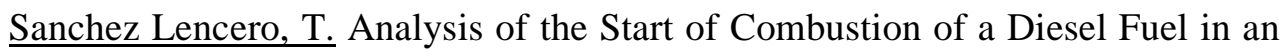
HCCI Process through an Integral Chemical Kinetic Model and Experimentation, T. Energy \& Fuels; 2008. 987-995

18. Heywood, J.B. "Internal Combustion Engine Fundamentals". McGraw-Hill Book Company. Singapore (Singapore). 1998.

19. Xingcai, L. Wei, C. Libin, J. Zhen, H. The effects of external exhaust Gas recirculation and Cetane number improver on the gasoline homogeneous charge compression ignition engines. Combust. Sci. and Tech. (2006) 178:1237-1249.

20. Shi, L. Cui, Y. Deng, K. Peng, H. Chen, Y. Study of low emission homogeneous charge compression ignition (HCCI) engine using combined internal and external exhaust gas recirculation (EGR). Energy 31, 2006. 26652676.

21. Yasar, H, Soyhan, H.S. Walmsley, H. Head, B. Sorusbay, C. Double-Wiebe function: An approach for single-zone HCCI engine modeling. Applied thermal Engineering 28 (2008) 1284-1290.

22. Soyhan, H.S. Yasar, H. Walmsley, H. Head, B. Kalghatgi, G.T. Sorusbay, C. Evaluation of heat transfer correlation for HCCI engine modeling. Applied Thermal Engineering 29(2009) 541-549.

23. Miller, J.A., Bowman, C.T. (1989). Mechanism and modeling of nitrogen chemistry in combustion. Prog. Energy Combust. Sci., 15, 287-338.

24. Turns, S.R. (1995). Understanding $\mathrm{NO}_{\mathrm{x}}$ formation in nonpremixed flame: Experiments and modeling. Prog. Energy Combust. Sci., 21, 361-385. 
25. Xingcai, L. Yuchun, H. Libin, J. Linlin, Z. and Zhen, H. Heat Release Analysis on Combustion and Parametric Study on Emissions of HCCI Engines Fueled with 2-Propanol/n-Heptane Blend Fuels. Energy Fuels, 2006, 20, 18701878

26. Ruizhi, S. Ke, L.Feng, Y. Liu, S. Performance and Emissions Characteristics of DME Engine with High Ratio of EGR. Energy Fuels, 2009, 23, 5460-5466.

27. Haifeng, L. Mingfa, Y. Bo, Z. Zunqing, Z. Effects of Inlet Pressure and Octane Numbers on Combustion and Emissions of a Homogeneous Charge Compression Ignition (HCCI) Engine. Energy and Fuels, 2008, 22, 2207-2215.

28. Peng, Z. Zhao, H. Ma, T. Ladommatos, N. Characteristic of Homogeneous charge Compression Ignition (HCCI) combustion and Emissions of n-Heptane. Combust. Sci. and Tech., 2005, 177, 2113-2150.

\section{FIGURES CAPTIONS}



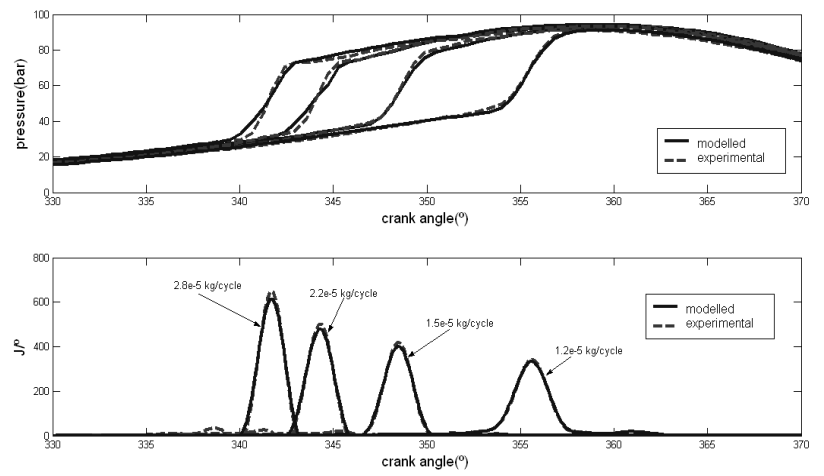

Figure 1. Combustion Chamber pressure and the HRR in HCCI combustion mode versus crank angle for a constant angular speed of 1200 RPM and inlet temperature of $18^{\circ} \mathrm{C}$. Compression ratio of 19:1.

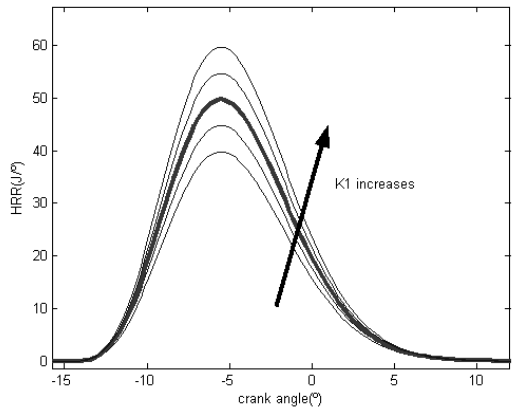

Analytical HRR versus K1 (a)

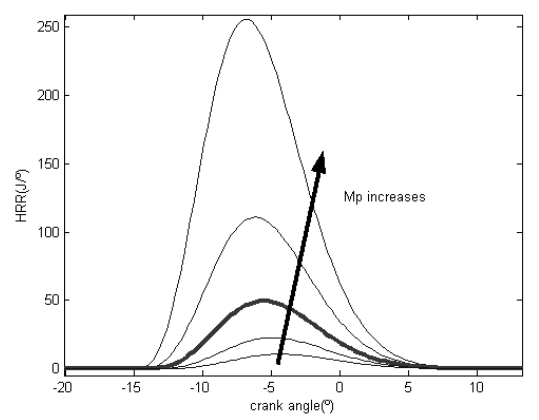

Analytical HRR versus Mp (c)

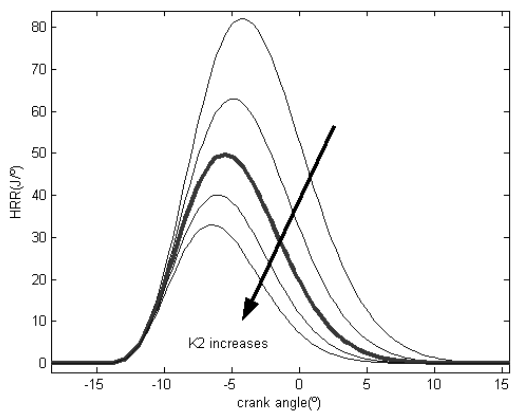

Analytical HRR versus K2 (b)

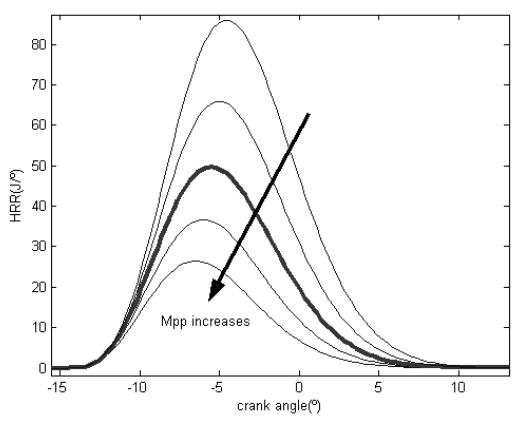

Analytical HRR versus Mpp (d) 
Figure 2. Analysis of HRR shape versus different parameters of the functional law.

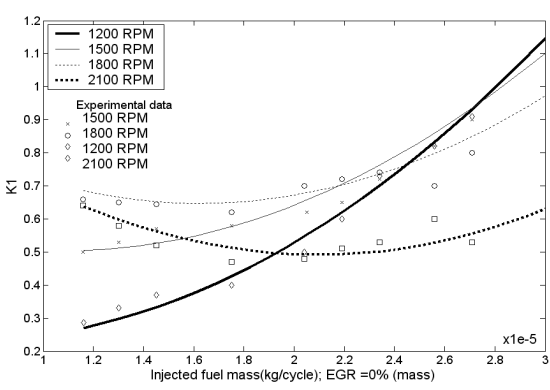

(a1)

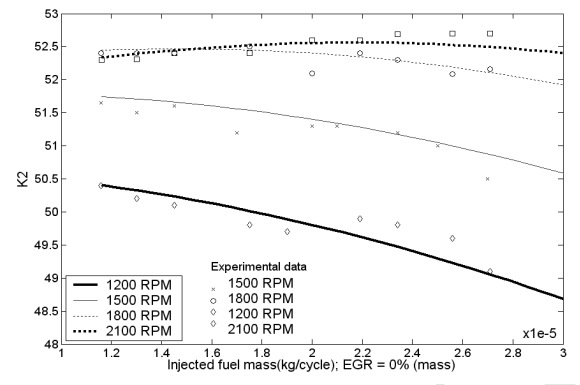

(a2)

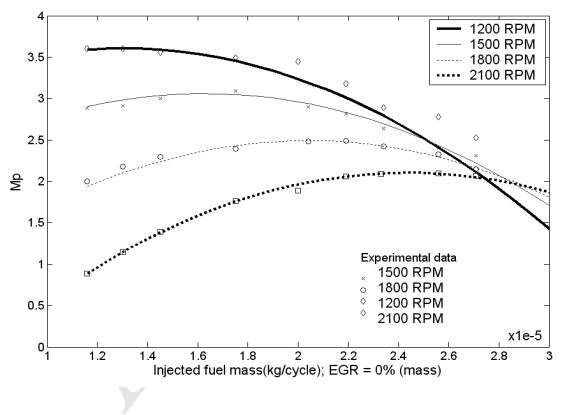

(a3)

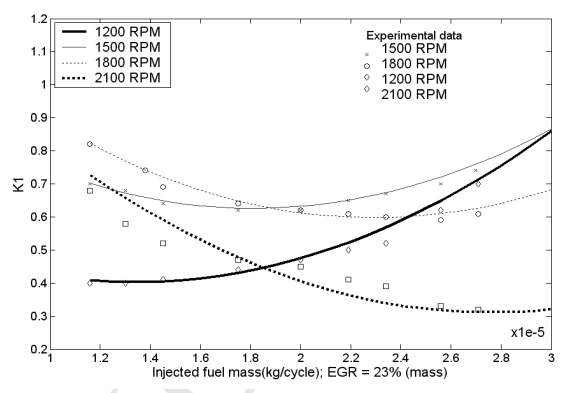

(b1)

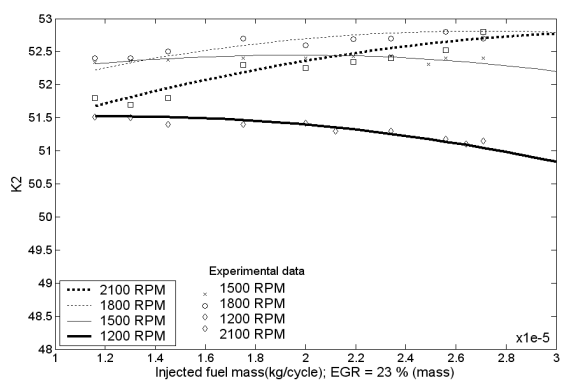

(b2)

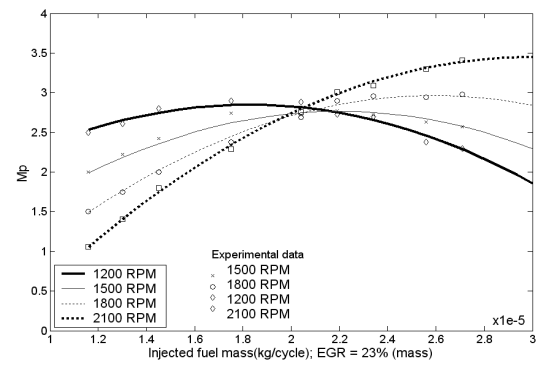

(b3) 


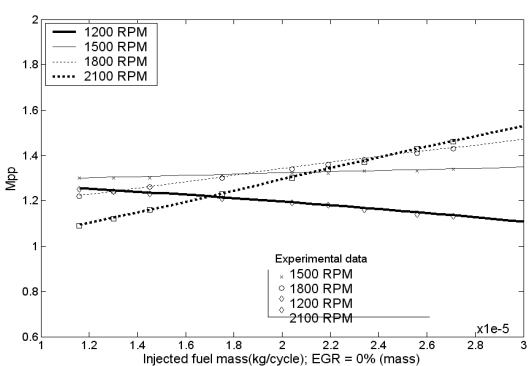

(a4)

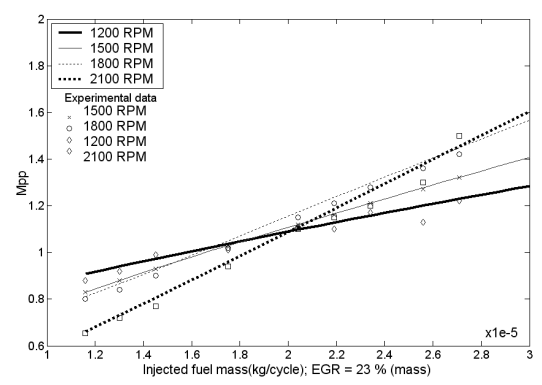

(b4)

Figure 3. Analysis of analytical law parameters versus the injected fuel mass for two EGR rate percentages.
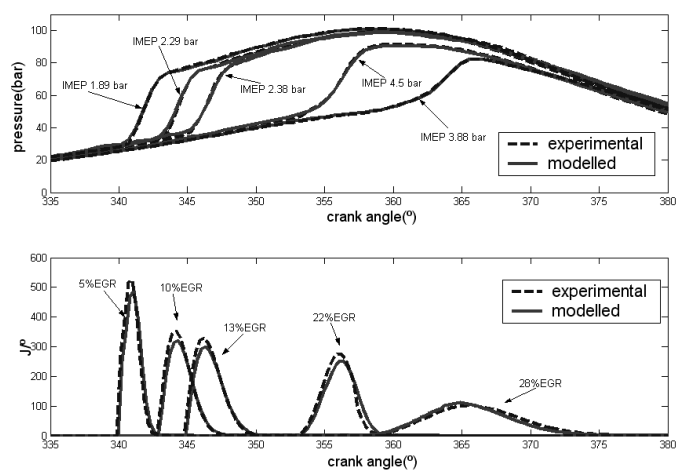

Figure 4. Measured and predicted cylinder pressure and HRR in HCCI combustion mode (engine speed is $2100 \mathrm{RPM}$, constant fuel consumption $2.75 \mathrm{e}^{-5} \mathrm{~kg} / \mathrm{cycle}$, initial $\Phi=0.46$ and different EGR rates).
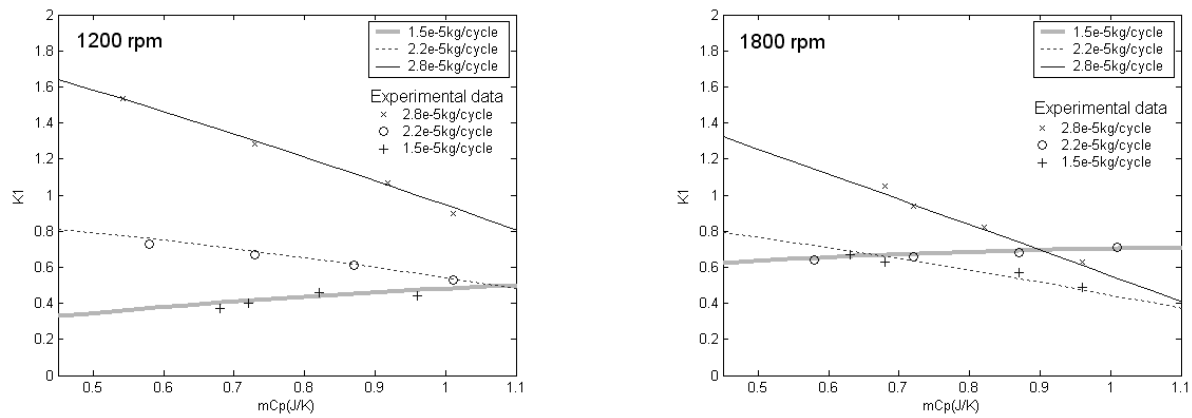
(a1)

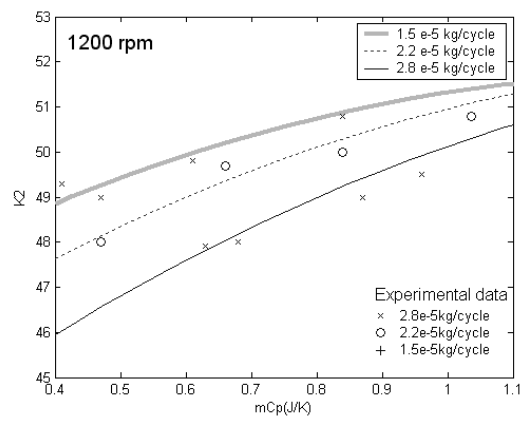

(a2)

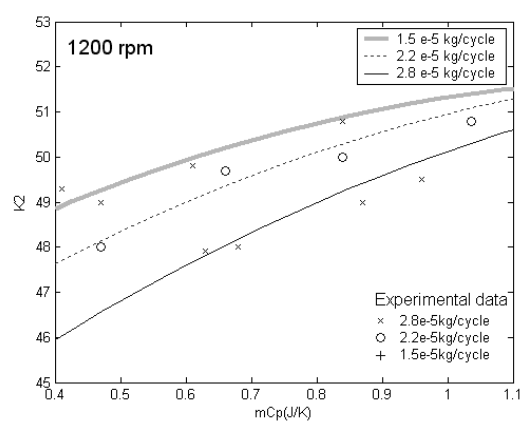

(a3)

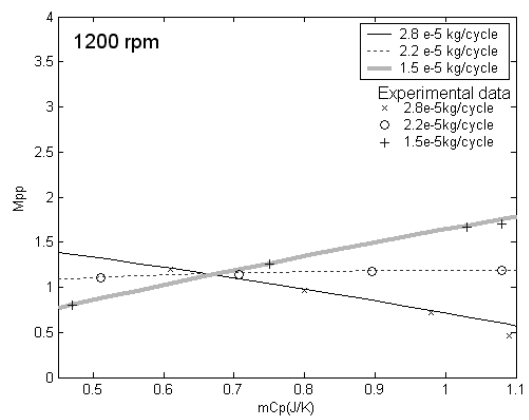

(a4) (b1)

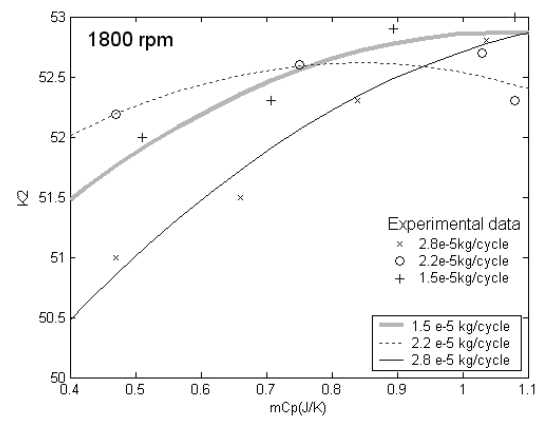

(b2)

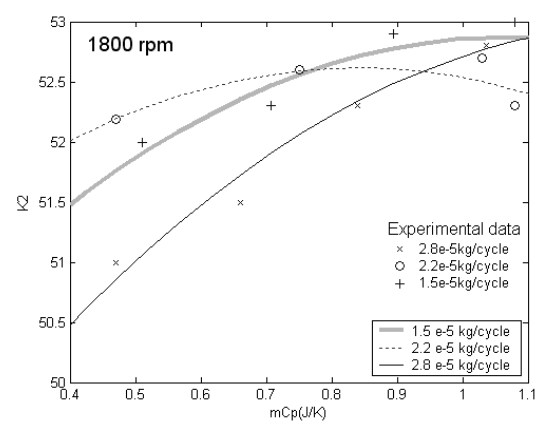

(b3)

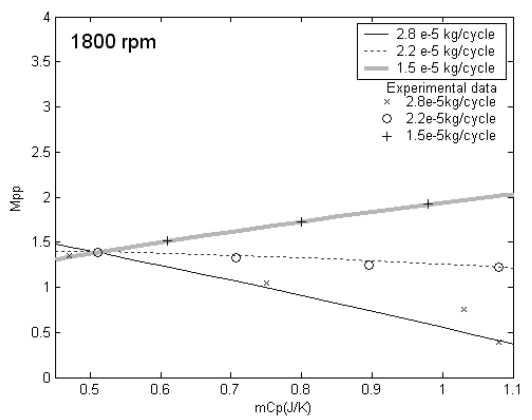

(b4)

Figure 5. Analysis of the sensitivity of the analytical law parameters versus EGR rate for two engine speeds.

\section{TABLES}




\begin{tabular}{cc}
\hline Diesel Fuel & Properties \\
\hline Density $\left(1\right.$ atm and $\left.15^{\circ} \mathrm{C}\right)$ & $820-845 \mathrm{~kg} / \mathrm{m}^{3}$ \\
Stoichiometric A/F ratio & 14.5 \\
Formula & $\mathrm{C}_{\mathrm{n}} \mathrm{H}_{1.8 \mathrm{n}}$ \\
LHV & $42.5 \mathrm{MJ} / \mathrm{kg}$ \\
Viscosity (at $\left.40^{\circ} \mathrm{C}\right)$ & $2-4.5 \mathrm{~mm}^{2} / \mathrm{s}$ \\
Cetane index & 46 \\
\hline
\end{tabular}

Table 1. Data for EN590 diesel properties

\begin{tabular}{|c|c|c|c|c|c|c|c|}
\hline Figure & $\mathrm{K} 1$ & $\mathrm{~K}$ & $\mathrm{Mp}$ & Mpp & $\begin{array}{c}\text { HRR maximum } \\
\text { value }(\mathbf{J})\end{array}$ & $\begin{array}{l}\text { HRR maximum } \\
\text { angle }\left(^{\circ}\right) \text { BTDC }\end{array}$ & $\begin{array}{l}\text { Combustion } \\
\text { Duration }\left({ }^{\circ}\right)\end{array}$ \\
\hline \multirow{5}{*}{ (a) } & 0.4 & 50 & 3.75 & 0.73 & 38 & 6 & 24 \\
\hline & 0.4 & 50 & 3.75 & 0.73 & 43 & 6 & 24 \\
\hline & 0.5 & 50 & 3.75 & 0.73 & 49 & 6 & 24 \\
\hline & 0.5 & 50 & 3.75 & 0.73 & 56 & 6 & 24 \\
\hline & 0.6 & 50 & 3.75 & 0.73 & 59 & 6 & 24 \\
\hline \multirow{5}{*}{ (b) } & 0.5 & 40 & 3.75 & 0.73 & 82 & 8 & 28 \\
\hline & 0.5 & 45 & 3.75 & 0.73 & 63 & 6.6 & 26 \\
\hline & 0.5 & 50 & 3.75 & 0.73 & 49 & 6 & 24 \\
\hline & 0.5 & 55 & 3.75 & 0.73 & 40 & 5 & 20 \\
\hline & 0.5 & 60 & 3.75 & 0.73 & 31 & 3 & 18 \\
\hline \multirow{5}{*}{ (c) } & 0.5 & 50 & 3.00 & 0.73 & 10 & 4 & 20 \\
\hline & 0.5 & 50 & 3.37 & 0.73 & 25 & 5 & 22 \\
\hline & 0.5 & 50 & 3.75 & 0.73 & 49 & 6 & 24 \\
\hline & 0.5 & 50 & 4.12 & 0.73 & 105 & 7 & 25 \\
\hline & 0.5 & 50 & 4.75 & 0.73 & 250 & 8 & 26 \\
\hline \multirow[t]{2}{*}{ (d) } & 0.5 & 50 & 3.75 & 0.58 & 85 & 7 & 26 \\
\hline & 0.5 & 50 & 3.75 & 0.65 & 63 & 6.4 & 25 \\
\hline
\end{tabular}




$\begin{array}{lllllcl}0.5 & 50 & 3.75 & \mathbf{0 . 7 3} & 49 & 6 & 24 \\ 0.5 & 50 & 3.75 & \mathbf{0 . 8 1} & 33 & 5.3 & 22 \\ 0.5 & 50 & 3.75 & \mathbf{0 . 8 7} & 22 & 4.7 & 20\end{array}$

Table 2. Analytical values corresponding to Figure 2

\begin{tabular}{|c|c|c|c|c|}
\hline Fuel/Air equivalence ratio & 0.36 & 0.5 & 0.6 & 0.7 \\
\hline $\begin{array}{l}\text { Injected fuel mass } \\
\text { (kg/cycle) }\end{array}$ & $1.2 \mathrm{e}^{-5}$ & $1.5 \mathrm{e}^{-5}$ & $2.2 \mathrm{e}$ & $2.8 \mathrm{e}^{-5}$ \\
\hline Air inlet (g/cycle) & 0.758 & 0.755 & 0.726 & 0.712 \\
\hline $\mathrm{P}_{\max }(\mathrm{bar})$ & 81 & 85 & 89 & 93 \\
\hline $\mathrm{HRR}_{\max }\left(\mathrm{J} /{ }^{\circ}\right)$ & 380 & 442 & 530 & 620 \\
\hline Combustion Duration $\left({ }^{\circ}\right)$ & 12 & 8 & 7 & 5 \\
\hline Smoke (Bosch \#) & 0.3 & 0.3 & 0.5 & 0.9 \\
\hline $\mathrm{NO}_{\mathrm{x}}$ emissions (ppm) & 145 & 160 & 260 & 350 \\
\hline Exhaust Temperature $\left({ }^{\circ} \mathrm{C}\right)$ & 380 & 423 & 560 & 602 \\
\hline CO emissions (ppm) & 220 & 298 & 350 & 402 \\
\hline HC emissions (ppm) & 150 & 238 & 365 & 444 \\
\hline IMEP (bar) & & 2.9 & 3.1 & 3.7 \\
\hline
\end{tabular}

Table 3. Combustion results for different air/fuel ratios at $1200 \mathrm{RPM}$

\begin{tabular}{|c|c|c|c|c|c|c|}
\hline \multirow[b]{2}{*}{ RPM } & cted mass & & & & & \\
\hline & \multicolumn{6}{|r|}{ Mpp } \\
\hline \multirow{4}{*}{1200} & $1.2 \mathrm{e}^{-5}$ & 0.3 & 0.3 & 50.5 & 3.46 & 1.25 \\
\hline & $1.5 \mathrm{e}^{-5}$ & 0.5 & 0.32 & 50.2 & 3.5 & 1.12 \\
\hline & $2.2 \mathrm{e}^{-5}$ & 0.6 & 0.71 & 49.5 & 2.5 & 1.17 \\
\hline & $2.8 \mathrm{e}^{-5}$ & 0.7 & 0.92 & 49.0 & 1.9 & 1.15 \\
\hline
\end{tabular}


Table 4. Parameters for simulated HRR corresponding to Figure 1

\begin{tabular}{|c|c|c|c|c|c|}
\hline$\%$ EGR rate $/ \mathrm{m} \cdot \overline{C_{p}}(\mathrm{~J} / \mathrm{K})$ & $5 \% / 0.5$ & $10 \% / 0.51$ & $20 \% / 0.65$ & $22 \% / 0.73$ & $28 \% / 0.9$ \\
\hline $\mathrm{P}_{\max }(\mathrm{bar})$ & 96 & 95 & 93 & 83 & 72 \\
\hline $\mathrm{HRR}_{\max }\left(\mathrm{J} /{ }^{\circ}\right)$ & 500 & 350 & 320 & 300 & 20 \\
\hline Combustion Duration $\left({ }^{\circ}\right)$ & 4 & 6 & 7 & 9 & 16 \\
\hline Smoke (Bosch \#) & 0.5 & 0.3 & 0.4 & 0.7 & 0.7 \\
\hline $\mathrm{NO}_{\mathrm{x}}$ emissions (ppm) & 367 & 261 & 190 & 120 & 82 \\
\hline $\mathrm{CO}$ emissions (ppm) & 350 & 412 & 436 & 469 & 501 \\
\hline $\mathrm{HC}$ emissions (ppm) & 229 & 292 & 334 & 413 & 490 \\
\hline Exhaust Temperature $\left({ }^{\circ} \mathrm{C}\right)$ & 560 & 499 & 472 & 442 & 403 \\
\hline BSFC $(\mathrm{kg} / \mathrm{kWh})$ & 0.380 & 0.351 & 0.289 & 0.261 & 0.273 \\
\hline IMEP (bar) & 1.84 & 2.29 & 2.38 & 4.50 & 3.88 \\
\hline
\end{tabular}

Table 5. Combustion results for different EGR rates at $2100 \mathrm{RPM}$ and $0.027 \mathrm{~g} / \mathrm{cycle}$

\begin{tabular}{|c|c|c|c|c|c|c|c|}
\hline RPM & $\begin{array}{c}\text { Injected mass } \\
\text { fuel } \\
(\mathrm{kg} / \mathrm{cycle})\end{array}$ & $\Phi$ & $\begin{array}{c}\% \text { EGR } \\
\text { rate(mass) }\end{array}$ & K1 & K2 & $\mathrm{Mp}$ & Mpp \\
\hline \multirow{5}{*}{2100} & & 0.34 & 8 & 0.35 & 50.26 & 2.64 & 1.36 \\
\hline & & 0.35 & 10 & 0.28 & 52.33 & 2.10 & 1.36 \\
\hline & $2.7 \mathrm{e}^{-5}$ & 0.38 & 13 & 0.25 & 51.62 & 2.60 & 1.22 \\
\hline & & 0.42 & 22 & 0.18 & 50.26 & 2.35 & 1.28 \\
\hline & & & 28 & 0.14 & 49.24 & 2.30 & 1.20 \\
\hline
\end{tabular}

Table 6. Parameters for simulated HRR 